“... NÃO SEI EXATAMENTE O QUE EU DEVO DIZER PARA FAZER COM QUE TENHA RELAÇÕES COMIGO...”: John Nash e as (in) Habilidades Sociais

\author{
"I DON'T KNOW EXACTLY WHAT I SHOULD SAY TO MAKE YOU HAVE \\ RELATIONSHIPS WITH ME...” John Nash and the (absence of) Social Skills
}

\author{
Patricia Carla Reis \\ Faculdade Boa Viagem - Recife - PE \\ patriciacarlareis@gmail.com \\ Anne Cavalcanti da Silva \\ Faculdade Boa Viagem - Recife - PE \\ annecavalcanti18@gmail.com \\ Edvânia de Oliveira \\ Faculdade Boa Viagem - Recife - PE \\ edvaniao1973@gmail.com
}

Submissão: 20/12/2019

Aprovação: $02 / 12 / 2020$

\title{
RESUMO
}

O presente caso para ensino apoia-se no filme, lançado em 2001, "Uma Mente Brilhante" ( $A$ Beautiful Mind), o qual é dirigido por Ron Howard, e se baseia na história real do matemático John Forber Nash (1928-2015). Procura-se por meio do relato de duas cenas do filme, estimular os discentes a refletirem sobre os conceitos de competência e habilidade social e o papel central desses conceitos no desenvolvimento humano e nas relações interpessoais. $\mathrm{O}$ caso tem sua aplicação destinada às disciplinas da área de administração e gestão de pessoas em conteúdos que foquem competências comportamentais, e pretende auxiliar o profissional de educação no trabalho deste tema em sala de aula.

Palavras-chave: Caso para ensino; Competência social; Habilidades sociais.

\begin{abstract}
The present case for teaching is based on Ron Howard's film, "A Beautiful Mind", which is based on the real story of mathematician John Forber Nash (1928-2015). It is sought through the reporting of two scenes of the film, to stimulate the students to reflect on the concepts of competence and social skills and the central role of these concepts in human development and interpersonal relations. The case has its application destined to the disciplines of the area of administration and management of people in contents that focuses behavioral competences and intends to assist the professional of education in the work of this theme in the classroom.
\end{abstract}

Keywords: Case for teaching; Social competence; Social skills. 


\section{O FILME}

O filme "Uma Mente Brilhante" conta a história do matemático John Forber Nash que 8nasceu no dia 13 de junho de 1928, em Bluefield, na Virgínia Ocidental, nos Estados Unidos. Nash, interpretado por Russel Crowe, é um matemático formado pela Universidade de Carnegie Mellon, com doutorado pela Universidade de Princeton, e com uma inteligência acima da média em matemática, que se refletia nas suas habilidades com os números, fórmulas e teoremas, tentando inclusive se destacar dos demais por meio da elaboração de sua própria teoria. Em contrapartida à sua inteligência matemática, Nash não era tão inteligente ao lidar com as pessoas; o próprio relata que uma de suas professoras dizia que ele tinha entrado duas vezes na fila do cérebro e nenhuma vez na fila do coração. Afirmava não gostar das pessoas e não ser querido por elas.

Durante sua vida acadêmica, John Nash evitava comparecer a palestras e aulas, aprendendo sozinho, sem a ajuda de professores; sua meta era encontrar uma ideia original. Sua tese de doutorado, conhecida como o "Equilíbrio de Nash", lhe rendeu, 45 anos depois, o Prêmio de Ciências Econômicas em Memória de Alfred Nobel, revolucionando a tomada de decisões nas estratégias econômicas.

Nash se tornou professor, lecionou na Universidade de Princeton e no Instituto de Tecnologia de Massachusetts (MIT). Entretanto, no início de sua carreira como docente, ele não se encantava com a ideia de ser professor, externando por diversas vezes a sua sensação de perda de tempo quando estava em sala de aula, preferindo a atividade de pesquisa. Porém, foi justamente por uma de suas alunas, Alicia, por quem Nash se apaixonou e com quem se casou. Alicia conseguiu se aproximar dele e vencer a barreira de distanciamento que ele construía entre si e as demais pessoas.

Durante seu casamento com Alicia, os sintomas de esquizofrenia, tais como alucinações e delírios, já apresentados por Nash, passaram a se agravar, levando à sua internação e ao diagnóstico desta doença. Nash passou por diversos tratamentos, entre eles o choque elétrico, e ao longo dos anos foi se recuperando lentamente, aprendendo a lidar com a ocorrência dos sintomas causados pela doença.

\section{Cena 1 - A paquera}

Em um bar de alguma cidade do estado da Pensilvânia, nos Estados Unidos, em meados dos anos 40, um grupo de amigos joga sinuca, entre eles, John Nash. Neste momento, eles avistam duas bonitas jovens no balcão: uma delas está envolvida com um dos amigos, enquanto a outra está sozinha. Os amigos de Nash o desafiam e o encorajam a cortejar a moça, um deles diz: "A sorte favorece os bravos", enquanto outro the dá um tapinha no ombro e fala: "Paga pra ver". John Nash que não é humilde em sua colocação afirma aos amigos: "Senhores, eu acho que tenho que lembrar a todos de que minhas chances de sucesso aumentam a cada tentativa" e vai ao encontro da loira no balcão do bar. Um de seus amigos afirma neste momento: "Essa vai ser clássica!", duvidando da habilidade de Nash com as mulheres.

Ele vai até ela e senta-se ao seu lado no bar. Inicialmente, acontece um período de silêncio em que os dois trocam sorrisos e olhares, porém esse silêncio acaba se prolongando e ele nada fala. A moça então, constrangida pelo silêncio dele que foi quem se aproximou, sugere: "Que tal me pagar uma bebida?", na intenção de facilitar a aproximação; porém, Nash ignora o que ela diz e quando começa a falar é nítida a surpresa da jovem moça ao ouvir dele: "É que eu não sei exatamente o que eu devo dizer para fazer com que tenha relações comigo. Mas podíamos fingir que eu já disse. É apenas uma mera troca de fluídos orgânicos. Que tal irmos direto ao assunto?". A garota fica por um segundo sem ação diante do repúdio que a 
atitude dele causou, então ela ironicamente diz: "Que romântico!", e o esbofeteia no rosto, saindo muito brava e proferindo em voz alta para todo o bar escutar: “...e tenha uma boa noite, idiota!", ao que todos ficam estupefatos sem entender o que de fato aconteceu. Enquanto Nash, desconsolado, massageia seu rosto que ficou dolorido, um dos amigos que está com ele comenta em tom irônico: "Olha, adorei a troca de fluídos orgânicos, foi...muito criativo!", amigo este que no decorrer do filme descobrimos não ser real, e sim uma das alucinações que ele costumava ter.

\section{Cena 2 - A aula}

Tempos depois, John Nash, agora doutor, inicia sua atividade de docente no MIT. Nash vai para a sala de aula contra a sua vontade, visivelmente insatisfeito com essa atividade, já que sempre preferiu ser pesquisador a ser professor. Os alunos ao vê-lo, de imediato se ajeitam na carteira, ficando quase imóveis. Nash ao adentrar a sala de aula observa os alunos e ao invés do cordial "bom dia", fala de forma irônica: "As mentes ávidas do amanhã". Neste momento, um forte barulho se inicia, resultado de uma obra de construção civil que está sendo realizada do lado de fora desta sala de aula. Nash caminha até a janela, e sem mencionar palavra alguma, simplesmente fecha de forma grosseira a janela da sala deixando o ambiente sem ventilação, e um de seus alunos logo pergunta: "Podemos deixar uma (janela) aberta professor? Está muito quente aqui", e Nash responde: "O seu conforto vem depois da necessidade de escutar a minha própria voz". Logo a seguir, o professor após folhear algumas páginas de um livro em silêncio, joga-o no cesto de lixo, virando-se para escrever uma equação no quadro enquanto profere as seguintes palavras: "Na minha opinião, essas aulas são uma perda do seu e o que é muito pior, do meu tempo, mas já que estamos aqui, bom... Vocês podem vir às aulas ou não... Fazer os deveres se vocês quiserem... E pronto, começamos..."

Neste momento, de maneira inesperada, uma de suas alunas bastante bonita levanta-se e vai em direção à janela, chamando a atenção dos demais alunos. Ela abre a janela e o professor ao perceber tenta impedi-la começando por alertá-la: "Moça...", mas ela o olha firme e ele não continua a frase. Ela se direciona ao pessoal da construção lá fora, e de forma gentil e simpática diz: "Dá licença... Dá licença... Olá! É... Nós temos um probleminha: está muito quente aqui dentro com a janela fechada e muito barulhento com ela aberta. Será que não dava para quebrar o galho e sei lá, fazer outro serviço? Vai durar só uns 45 minutos. Muito obrigada!" Atendendo ao pedido, um dos trabalhadores diz: "Só por você, hem?" e param então de fazer barulho e se organizam para um outro trabalho.

O professor observa tudo, surpreso com o comportamento da moça. Visivelmente, de forma desconcertada e com um leve sorriso nos lábios, continua a aula, completando: "Como vocês irão ver, o cálculo com muitas variáveis oferece soluções diversas para o mesmo problema", e os alunos em uníssono fazem "hummm...", vendo-o sorrir para ela. Ela, por sua vez, também o olha segura de si, e sorrindo, continua abrindo as demais janelas.

\section{NOTAS DE ENSINO}

\section{Síntese das notas de ensino}

Este caso tem como tema central as habilidades sociais e sua importância para os relacionamentos interpessoais e para a vida das pessoas, como um todo. Utilizando-se de duas pequenas cenas do filme "Uma Mente Brilhante", procura-se despertar o interesse dos discentes das áreas de administração e gestão de pessoas para esse tema, de maneira a auxiliar 
os docentes a desenvolverem neles, o entendimento do que são as habilidades sociais, sua importância, e a refletirem sobre o desenvolvimento de suas próprias habilidades. John Nash, matemático interpretado no filme por Russel Crowe, sofre de esquizofrenia, e por isso, embora seja um gênio na matemática (competência técnica), tem algumas dificuldades no que diz respeito às suas habilidades sociais e ao relacionamento interpessoal (competências comportamentais), sendo as cenas escolhidas, exemplos didáticos adequados de como as habilidades sociais, ou a falta delas, interferem no convívio social. O caso não só faz uso das cenas do filme em questão, mas sugere a leitura prévia de um texto que permitirá aos alunos maior entendimento sobre o assunto e, após a resolução das questões levantadas pelo caso, a realização de debate para maior aprofundamento. Sugere-se ainda uma bibliografia de apoio para aqueles que quiserem aprender mais sobre o tema, com autores como os Del Prette e Caballo, reconhecidos amplamente por seu trabalho em treinamento de habilidades sociais.

\section{Fontes de dados}

Trechos do filme: "Uma Mente Brilhante", dirigido por Ron Howard, e estrelado por Russel Crowe. O filme estreou no cinema em 2001, e foi vencedor do Oscar no ano de 2002, nas categorias de melhor filme, melhor roteiro adaptado, diretor e melhor atriz coadjuvante, além de ser indicado para outras categorias desta mesma premiação. $O$ filme conta a vida pessoal e profissional de John Nash, um notável matemático que sofria de esquizofrenia e que apesar de muitos momentos difíceis provocados pela doença, contribuiu consideravelmente para várias áreas com suas teorias, recebendo, entre outros reconhecimentos, o importantíssimo Prêmio de Ciências Econômicas em Memória de Alfred Nobel, em 1994. As cenas sugeridas para este caso apresentam maus exemplos de competência social do personagem principal, e em contrapartida, um exemplo de alguém socialmente competente frente a um determinado problema. $\mathrm{Na}$ cena em questão, uma de suas alunas aumenta a probabilidade de conseguir o que ela e todos os alunos almejavam ao usar adequadamente seu repertório de habilidades sociais; o que conseguiu de fato: uniu a necessidade de assistir aula a um maior conforto para todos. Ao longo de sua vida, Nash passa por tratamentos mais severos nos momentos em que sua doença se revelou de maneira mais aguda, até se convencer que teria sempre a necessidade de tomar remédios para controle de seu transtorno. Com o tempo, ele aprendeu a lidar com seus sintomas de maneira mais produtiva, aperfeiçoando, inclusive, suas habilidades sociais, o que lhe permitiu uma melhoria na sua qualidade de vida como um todo e uma melhor reintegração social na fase de remissão da doença, tanto que ele não só voltou a dar aulas, mas passou a fazê-lo com verdadeiro prazer e bom relacionamento com os alunos.

\section{Área de conhecimento}

Administração e gestão de pessoas com foco em competências comportamentais e mais especificamente, competência social e habilidades sociais.

\section{Público-alvo}

Alunos de disciplinas da área de administração e gestão de pessoas.

\section{Objetivos pedagógicos}

- Entender o que são as habilidades sociais e o impacto delas na vida em geral; 
- Compreender a importância do desenvolvimento das habilidades sociais para uma maior possibilidade de consecução dos objetivos nas interações, refletindo em maior equilíbrio de ganhos e perdas entre os envolvidos;

- Refletir sobre suas próprias habilidades sociais e o quanto precisa desenvolver cada uma delas para o aperfeiçoamento das relações interpessoais, tanto pessoais quanto profissionais.

\section{Estratégias de ensino}

\section{Antes da aula (com 1 semana de antecedência):}

A - Com uma semana de antecedência, deve-se disponibilizar aos alunos o texto "Habilidades Sociais: conceitos e campo teórico-prático" (DEL PRETTE, A; DEL PRETTE, Z.A.P., 2006). A orientação será para que leiam o texto e entreguem na aula seguinte uma pequena resenha crítica abordando e comentando 3(três) aspectos que tenham chamado a atenção do aluno durante a leitura.

\section{Durante a aula (2 horas e 30 minutos):}

B - Solicitar aos alunos para formarem grupos com 4 a 6 participantes. Se a turma for pequena, pode-se formar grupos menores ou até mesmo duplas. Aconselha-se, mesmo em turmas grandes, não fazer grupos com mais de 6 integrantes para não dispersar os mesmos e garantir a participação de todos. Os alunos deverão, em grupo, compartilhar e discutir sobre as respostas da atividade realizada em casa. ( $\mathrm{B}=25$ minutos)

C - Promover uma rápida discussão, em plenária, sobre a atividade realizada em casa, permitindo que 3(três) a 5(cinco) alunos de grupos aleatórios comentem. Tal etapa, permitirá ao docente realizar uma pequena introdução ao tema a ser trabalhado durante esta aula. Aproveitar para, ao término da discussão, receber as resenhas críticas solicitadas uma semana antes $(\mathrm{C}=25$ minutos $)$;

D - Exibir as duas cenas já editadas, a saber: a cena da paquera em um bar, a qual se apresenta neste artigo como cena 1, denominada de "A paquera" (1 minuto e 45 segundos); e a cena 2 , denominada de "A aula" (2 minutos e 7 segundos);

E - Distribuir uma cópia do caso de ensino: “... NÃO SEI EXATAMENTE O QUE EU DEVO DIZER PARA FAZER COM QUE TENHA RELAÇÕES COMIGO...”: John Nash e as (in) Habilidades Sociais para cada grupo, contendo a descrição das cenas já assistidas e as questões para discussão. Desta forma, os alunos poderão ler e reler o caso quantas vezes forem necessárias para poderem responder às questões com maior segurança $(\mathrm{D}+\mathrm{E}=25$ minutos$)$;

F - É aconselhável, após responderem as questões, dar um intervalo para que os alunos possam descansar e se organizar para a continuação da aula ( $\mathrm{F}=10$ minutos);

$\mathrm{G}$ - Realizar debate com todos os grupos sobre as questões pertencentes ao caso. Conforme o debate for ocorrendo, aproveitar para fazer outras perguntas estimuladas pelo próprio debate, de maneira a enriquecê-lo e aprofundar um pouco mais sobre o tema juntamente com a participação ativa de todos $(\mathrm{G}=40$ minutos $)$; 
$\mathrm{H}$ - Solicitar aos alunos que desfaçam os grupos e sentem-se formando um grande círculo. Explicar a definição e a importância de se fazer o "automonitoramento" para reflexão e avaliação dos pontos fortes e fracos de cada um em relação às suas habilidades sociais para que possam direcionar melhor seus esforços para o desenvolvimento e aperfeiçoamento dessas habilidades, solicitando aos mesmos que registrem ao menos uma habilidade social que considerem melhor desenvolvida por si mesmos e uma habilidade social que precisem desenvolver ou aperfeiçoar $(\mathrm{H}=10$ minutos $)$;

I - Após todos terem refletido sobre seus "automonitoramentos", pedir que comentem entre as habilidades sociais que registraram, aquela que acreditam ser, no momento, a mais relevante para desenvolverem e o porquê. Após a reflexão, o professor apontará a importância de os alunos construírem meios para desenvolverem estas habilidades, destacando que as respostas são de cunho individual. ( $\mathrm{I}=25$ minutos)

\section{Questões para a discussão do caso em sala de aula}

1. Na cena do bar, por que Nash não conseguiu conquistar a loira, já que aparentemente, ela também o estava paquerando?

2. Na opinião de vocês, como ele poderia ter agido, de maneira a aumentar suas chances de conseguir o que queria?

3. Na cena da aula, como vocês descreveriam a atitude de Nash perante os alunos e o problema que surgiu?

4. Quais habilidades sociais a aluna utilizou em seu discurso para conseguir com que os operários parassem a obra, e os estudantes pudessem então abrir a janela e assistir a aula?

\section{Base teórico-conceitual}

Afinal, o que são habilidades sociais ou o que faria uma pessoa ser considerada socialmente competente? Segundo Del Prette e Del Prette (2010, p. 33), "pessoas socialmente competentes são as que contribuem na maximização de ganhos e na minimização de perdas para si e para aquelas com quem interagem" e ainda:

[...] o desempenho socialmente competente é aquele que [...] expressa uma leitura adequada do ambiente social, ou seja, decodifica corretamente os desempenhos esperados, valorizados e efetivos para o indivíduo em sua relação com os demais. (DEL PRETTE; DEL PRETTE, 2010, p. 33)

Assim, quando uma pessoa age de maneira socialmente competente há sempre uma maior possibilidade de consecução dos objetivos esperados nessas interações, e critérios como a manutenção ou melhora da autoestima; maior equilíbrio de ganhos e perdas entre os envolvidos na interação; manutenção ou melhora da qualidade da relação; e, respeito e ampliação dos direitos humanos básicos, também se fazem presentes. Isto é, quanto mais esses critérios acontecem, simultaneamente, em uma relação, maior é a competência social e as relações pessoais e profissionais se tornam mais produtivas, satisfatórias e duradouras, o que acaba gerando maior qualidade de vida como um todo. (DEL PRETTE; DEL PRETTE, 2010). 
De qualquer maneira, conseguir os objetivos esperados em uma relação, não pode ser um critério a ser avaliado de forma isolada, já que:

Uma pessoa pode, devido a outros fatores, não atingir os objetivos pretendidos na interação e, ainda assim, ser considerada competente sob os demais critérios. Por outro lado, ela pode atingir os objetivos de uma forma que não seria considerada competente sob os demais critérios, por exemplo, por meio da agressão ou da coerção que prejudicam imediatamente, ou em médio prazo, a qualidade da relação, a autoestima e o equilíbrio de poder. (DEL PRETTE; DEL PRETTE, 2010, p. 35)

$\mathrm{Na}$ prática é fundamental avaliar tanto como as pessoas agem, como também as reações que seus comportamentos provocam em outras pessoas, pois é esperado que o comportamento socialmente hábil gere mais reforços positivos do que punições. Portanto, para se ter uma melhor compreensão do grau de habilidade social de uma pessoa, não só se deve observar o conteúdo do seu comportamento, como também, as consequências geradas por tais comportamentos. (DEL PRETTE; DEL PRETTE, 2010)

Caballo (1986 apud CABALLO, 2006) concorda com essa visão, afirmando que tanto o comportamento como suas consequências são essenciais para poder avaliar um comportamento como sendo socialmente hábil. E acrescenta sua própria definição:

\begin{abstract}
O comportamento socialmente hábil é esse conjunto de comportamentos emitidos por um indivíduo em um contexto interpessoal que expressa sentimentos, atitudes, desejos, opiniões ou direitos desse indivíduo de modo adequado à situação, respeitando esses comportamentos nos demais, e que geralmente resolve os problemas imediatos da situação enquanto minimiza a probabilidade de futuros problemas. (CABALLO, 1986 apud CABALLO, 2006, p. 6)
\end{abstract}

Para o desenvolvimento dessas habilidades sociais, espera-se que a pessoa valorize a aperfeiçoe aquelas habilidades sociais que já possui e desenvolva aquelas que são inexistentes ou pouco representativas em seu comportamento, o que só pode ser feito por meio de um processo de autoconhecimento e de uma autoavaliação realista e honesta.

Essa autoavaliação, cujo intuito é analisar suas próprias habilidades sociais e compreender quais são os pontos fortes e fracos a serem trabalhados, é também chamada de "automonitoramento". O automonitoramento é concebido, segundo Del Prette e Del Prette (2010, p.62), "como uma habilidade metacognitiva e afetivo-comportamental pela qual a pessoa observa, descreve, interpreta e regula seus pensamentos, sentimentos e comportamentos em situações sociais."

As pessoas que aprendem a monitorar a si mesmas são mais conscientes dos seus comportamentos, podendo trabalhar suas potencialidades e pontos vulneráveis em busca de uma melhor competência social. Já aquelas que têm dificuldade em monitorar a si mesmas, apresentam respostas mais automáticas aos estímulos ambientais e não conseguem promover o desenvolvimento mais pleno de sua competência social. (DEL PRETTE; DEL PRETTE, 2010)

\title{
Bibliografia recomendada para a consecução dos objetivos de aprendizagem
}

CABALLO, Vicente E. Manual de avaliação e treinamento das habilidades sociais. São Paulo: Livraria Editora, 2006.

DEL PRETTE, Almir; DEL PRETTE, Zilda A. P. Psicologia das relações interpessoais. Vivências para o trabalho em grupo. 8. ed. Rio de Janeiro: Vozes, 2010. 
DEL PRETTE, Almir; DEL PRETTE, Zilda A. P. Habilidades sociais: conceitos e campo teórico-prático. Disponível em: <http://www.rihs.ufscar.br/wpcontent/uploads/2015/02/habilidades-sociais-conceitos-e-campo-teorico-pratico-1.pdf $>$. Acesso em: 08 ago. 2019.

RIHS/UFSCar. Grupo de relações interpessoais e habilidades sociais da Universidade Federal de São Carlos. Disponível em: < http://www.rihs.ufscar.br/>. Acesso em: 08 ago. 2016.

\section{REFERÊNCIAS}

CABALLO, Vicente E. Manual de avaliação e treinamento das habilidades sociais. São Paulo: Livraria Editora, 2006.

DEL PRETTE, Almir; DEL PRETTE, Zilda A. P. Psicologia das relações interpessoais. Vivências para o trabalho em grupo. 8. ed. Rio de Janeiro: Vozes, 2010.

DEL PRETTE, Almir; DEL PRETTE, Zilda A. P. Habilidades sociais: conceitos e campo teórico-prático. Disponível em: <http://www.rihs.ufscar.br/wpcontent/uploads/2015/02/habilidades-sociais-conceitos-e-campo-teorico-pratico-1.pdf $>$. Acesso em: 08 ago. 2019.

RIHS/UFSCar. Grupo de relações interpessoais e habilidades sociais da Universidade Federal de São Carlos. Disponível em: < http://www.rihs.ufscar.br/>. Acesso em: 08 ago. 2016. 